\title{
Orden y Visión de Tres Tristes Tigres
}

\author{
"Not flimsy nonsense, but a web of sense" \\ Vladimir Nabokov, Pale Fire
}

El libro de Guillermo Cabrera Infante ha sido hasta ahora poco explorado. Los críticos que se han ocupado de él -y escasean todavía los estudios serios y extensos- coinciden, por otra parte, en el señalado interés por el lenguaje (o procedimientos lingüísticos) de la obra. ${ }^{1}$ Concediendo la importante función que desempeñan en la obra la estructura y el medio expresivo, me propongo establecer aquí la relación a relaciones de ese orden o forma particular con niveles de sentido que me parecen no menos importantes. El desarrollo de este trabajo podría formularse aproximadamente así: consideración detallada de la estructura del libro, en la perspectiva de sus significados más amplios; el libro en cuanto aprehensión de un aspecto de la realidad cubana que remite, a su vez, a una visión total de esa realidad y a la visión del mundo que ofrece allí el autor; y, para concluir, la cosmovisión del autor me llevará de nuevo a la manera de composición de la obra, influido de algún modo por uno de sus motivos más notables, el del final que es principio o recomienzo. La recapitulación a la inversa me servirá, además, para volver con más precisiones sobre el problema de ubicación genérica que, de entrada, se le plantea al lector del libro y que he de abordar por ello desde el inicio de mi análisis.

Contra lo que pueda a primera vista parecer, Tres tristes tigres tiene una estructura (sería mejor llamarla disposición u organización) ejecutada de acuerdo con un tiguroso plan. Tan minucioso es el orden de la obra,

1 Aunque Emir Rodríguez Monegal ha escrito un importante trabajo sobre la estructura de $T T T$, lleno de agudas observaciones en cuanto a sus temas, la mayor parte de su ensayo se dedica a caracterizar el lenguaje de la obra. La confrontación de este lenguaje con el de Rayuela es particularmente valiosa. Me refiero a "Estructura y significaciones de Tres tristes tigres" (Sur, no 320, septiem. bre-octubre de 1969). Un estudio pormenorizado de rasgos lingüísticos del libro es el de Nicolás Rosa, "Cabrera Infante: una patología del lenguaje", incluido en su Crítica y significación, Buenos Aires, 1970. 
que si de algo peca es tal vez de la abundancia de "cifras" o "rompecabezas" —así se titula significativamente una parte del libro-, algunos de los cuales provocarán en el lector la inquietud del enigma insoluble. Este carácter del libro hizo pensar a Cabrera Infante, en un principio, que "no sería entendido más que por un número muy reducido de personas que vivían en determinado lugar de La Habana y alrededor mío."" Pero no se interprete mal lo que trato de decir: TTT dista de ser una obra "hermética" en el sentido corriente que ha adquirido el vocablo, aunque sin duda lo es en el etimológico, por alusión a Hermes Trimegisto, padre de la magia y la alquimia y dios de las correspondencias. Cabrera Infante, en definitiva, da suficientes datos para descifrar los acertijos, para armar el rompecabeza, aunque alguna pieza no encuentre su lugar sino en el modelo originalmente concebido por el autor.

Todo lo antedicho desemboca en la siguiente afirmación, punto de partida de este trabajo: TTT es la reproducción gráfica de una particular operación de la memoria que el autor sintetiza en la cita de Lewis Carroll puesta de epígrafe al libro - "Y trató de imaginar cómo se vería la luz de una vela cuando está apagada." (Esfuerzo de la memoria que provoca, en primer lugar, el condenatorio "Tradittori", así, con dos tes, en cruce cargado de sentido con traduttori, de las páginas finales.) Aclaro más mi postulado. Arriba empleo intencionadamente el calificativo gráfica para referirme a reproducción. $Y$ es que, contrariamente a lo que ya se ha vuelto tópico sobre TTT -señalar la cualidad de lengua hablada del texto-, opino que la distribución de sus materiales, que explota lo visual hasta el efecto tipográfico y el diagrama, es un aspecto decisivo en la composición de la obra. ${ }^{3}$ Esa distribución contribuye a coordinar en un todo armónico las voces que el texto pretende transmitir o "traducir". Sentada esta premisa, paso a describir, en su coherente integridad, la ar. quitectura de TTT."

En obra tan poco convencional, que ha sido situada, con mayor o menor justeza, dentro de la "anti-literatura" y la "anti-retórica" (el mismo Cabrera Infante juega en alguna entrevista con nociones semejantes apli-

\footnotetext{
2 Ver la entrevista con Rita Guibert, "Guillermo Cabrera Infante: conversación sobre Tres tristes tigres", en la Revista Iberoamericana, nos, 76-77, juliodiciembre de 1971, p. 546. Declaraciones parecidas se recogen en otras entrevistas. 3 "Para mí la lectura está siempre en función de la impresión en cualquiera de sus formas: máquina de escribir, periódico, libro", dice Cabrera Infante en la mencionada entrevista con Rita Guibert, loc. cit., p. 538.

- Utilizo la edición Seix Barral de 1968 (la paginación es la misma, no obstante el cambio de formato, en la de 1971). Doy el número de página, en partntesis, al final de las citas.
} 
cadas a su libro, las de "anti-novela" y "meta-novela"), Ilama la aten ción que su texto esté delimitado por los tradicionales prólogo y epílogo Claro que los contenidos de este prólogo y epílogo burlan la expectativa habitual del lector, pero de todos modos fijan un principio y un fin qu el autor ha querido asociar a estos conceptos establecidos. Si el prólogo de una obra anticipa una cuestión que se trata en ella, el epílogo la resume continuando, o mejor, confirmando lo propuesto en el prólogo, entiquecido ya por la elaboración del cuerpo de la obra. El prólogo de TTT contiene la presentación del show de Tropicana por su maestro de ceremonias. El epílogo es un fragmento del discurso "sinfín" de la loca que suele (o solía) pronunciarlo en el Parque de los Enamorados, de la cual habla Silvestre en el capítulo II de "Bachata" (pp. 299-300). Prólogo y epílogo aparecen en $T_{i}^{*} T$ "T, según se verá, como dos miembros que se corresponden, dos emblemas grotescos de la misma enajenación, Escila y Caribdis de esta odisea nocturna.

Entre el prólogo y el epílogo se hallan siete secciones, tituladas, en este orden: "Los debutantes", "Seseribó", "La casa de los espejos", "Los visitantes", "Rompecabeza", "Algunas revelaciones" y "Bachata" (el índice que lleva la edición de 1971 facilita mucho la labor reconstructora del lector curioso y el crítico, ese lector "traicionero").

"Los debutantes" está compuesta de "una galería de voces", entre las que oímos aquellas que serán protagonistas de la obra: la de Silvestre, la de Silvio Sergio Ribot (Eribó) y la de Arsenio Cué. La voz de Códac introduce la primera parte del relato "Ella cantaba boleros" -que se desarrollará alternando con otros pasajes a lo largo del libro- y el segundo capítulo de esta historia cierra la sección. Una de las voces menores reaparecerá más adelante (Magdalena Crús), pero no volverán a transcribirse la de Delia Doce - corresponsal de la madre de Cuba Venegasy la de Beba Longoria, pues la función de ambas se agota aquí. Bajo los epígrafes de "Primera" y "Segunda" se nos presentan también confesiones de una mujer a su psiquiatra, que se intercalarán en el resto del libro hasta llegar a la "Oncena", situada de modo muy deliberado, según se verá en su oportunidad, al final, precediendo inmediatamente al epílogo. Las páginas con que se abre la sección de "Los debutantes" -relato de

"Julio Ortega la califica de "doble intento de anti-literatura", en La consemplación y la fiesta, Caracas, 1969, p. 173. Para la categoría de "anti-retórica" ver el trabajo antes citado de Nicolás Rosa, págs. 189 y siguientes. Sobre "antinovela" y "meta-novela", véase la entrevista con Albert Bensoussan en Insula, Núm. 286, septiembre de 1970, p. 4.

- "El libro, lo he dicho muchas veces, es una galería de voces", expresa el 2utor (entrevista con Rita Guibert, loc. cit., p. 543 ). 
ciertos episodios de la niñez- en realidad constituyen la primera de esas sesiones psiquiátricas, de manera que la última u "Oncena", también recuerdo de infancia, vuelve al comienzo (de la vida y de la obra). No es imprescindible saber en este punto (ni en ningún otro, a decir verdad) que la mujer psicoanalizada es Laura Díaz, personaje cuya importancia no se advertirá hasta la última parte del libro.

"Seseribó" es la primera de las piezas fundamentales del ensamblaje que voy describiendo (pienso en un gran rompecabeza y en las partes que ayudan a componer mejor el diseño, por su posición decisiva en la reconstrucción del todo). La narración de Ribot o Eribó, el músico intérprete (bongosero) y dibujante con mucho de intelectual, es seguida por dos fragmentos de "Ella cantaba boleros", separados (mejor, vinculados) por la "Tercera" confesión psiquiátrica y seguidos, a su vez, por la "Cuarta", que pone fin a la sección. Es importante hacer notar aquí que en el fluir de la conciencia de Ribot se reflejan los otros dos "tigres", Cué y Silvestre, de manera muy especial. Esto, a primera vista, no sorprende: son amigos, los unen intereses semejantes. Pero cuando se cae en la cuenta de que el fenómeno se repite con la misma intensidad en los otros dos, empieza uno a inquirir sobre la significación de estas correspondencias especulares.

"La casa de los espejos" - y el subtítulo insinúa la respuesta a la cuestión que se acaba de plantear- es la segunda de estas piezas centrales. Es ahora el turno de Cué, actor, musicólogo aficionado y escritor de vocación que no ha querido o podido serlo. A propósito de un encuentro con dos coristas (en compañia, por cierto, de Silvestre), Cué revive su frustrada relación con Laura Díaz, una de las "claves maestras" del libro, sobre la que habré de extenderme más adelante. El tono de elegía amorosa subsiste aun bajo la grotesca comedia del vestirse y maquillarse de las dos muchachas, Livia y Mirtila, que forma el capítulo II de esta sección. Como interrumpir la continuidad de esta narración (y lo mismo ocurre en la anterior, "Seseribó", y en "Bachata"), habría dispersado de modo inútil la atención del lector sobre un proceso esencial a la conciencia de Cué (y Eribó y Silvestre), el autor reserva para el final las interpolaciones, que ya se van volviendo habituales o esperadas, de las confesiones psiquiátricas y "Ella cantaba boleros", en el orden siguiente: "Quinta", "Ella cantaba boleros" y la brevísima "Sexta".

Ahora tendremos que aguardar hasta la última sección, "Bachata", para hallar la tercera pieza determinante. Es la que corresponde a Silvestre, escritor, amateur de música y actor potencial que interpreta personajes, vicariamente, desde su butaca de cine. Prefiero dejar la caracterización 
detallada de este pasaje para el lugar correspondiente, ajustándome a la ordenación del libro. Señalo solamente que con estos tres personajes se compone la triada de los tigres aludida en el título de la obra.

"Los visitantes" presenta una visión "extraña". del escenario de la obra, la de una pareja de turistas norteamericanos. La ironía de Cabrera Infante se multiplica aquí como en otra "casa de espejos". El turista, Mr. Campbell, es escritor y lo incorporado a TT'T es un cuento suyo (más literatura) que "traduce" su breve experiencia de La Habana y alrededores, cuento a su vez mal "traducido" del inglés norteamericano por otro personaje de la obra, Rine Leal. El cuento aparece en la mala versión de Rine y en la corregida por Silvestre (según se aclara en la página 439). La circunstancia de que el cuento de Campbell, quien con arreglo a la noticia biográfica que se reproduce más adelante (p. 439) es soltero, incluye los "reparos" o "correcciones" de su esposa, añade otras perspectivas irónicas: la ofrecida por Campbell mismo, que fabrica dos versiones "ficticias" de sus aventuras, y sobre todo, la del omnipresente inventor del libro, que ha puesto a estos dos personajes, Mr. y Mrs. Campbell, entre los concurrentes de Tropicana mencionados por el emsi en el prólogo. Es necesario señalar ahora, para la mejor comprensión de observaciones posteriores, que las ambigüedades de este juego literario apuntan, a fin de cuentas, a lo extraliterario: a la confusa impresión que deja en un testigo extranjero el "espectáculo" de La Habana, lo cual él es el primero en reconocer irónicamente. Esta hipotética mirada extranjera a Cuba es, por otra parte, indispensable al plan de la obra. Ella permite que la realidad que sirve de base al libro sea percibida también desde fuera, con un aspecto grotesco no menos auténtico que el "traducido" por los lúcidos personajes-narradores nativos.

La "Séptima" de las sesiones psiquiátricas, con que termina la sección, se hace eco del motivo de las deformaciones, confusiones y correcciones que la recorre. "El viernes le dije una mentira, doctor", comienza diciendo la paciente $\mathrm{y}$ enseguida pasa a rectificarse. Es oportuno indicar aquí que estas confesiones psiquiátricas son como las irrupciones de una corriente soterrada que copia a su manera motivos de los otros textos de la obra. (Se podría decir también que ellas forman como una serie de notas ampliatorias dentro del conjunto).

"Rompecabeza" y "Algunas revelaciones" presentan los hechos, o más bien, dichos, de Bustrófedon, con la circunstancia de su muerte. Se recoge aquí un repertorio de los juegos lingüísticos de Bustrófedon, que remedan los otros personajes principales, sus amigos. La sección. "Rompecabeza", en su mayor parte, se compone de las parodias de varios escritores cu- 
banos - Martí, Lezama Lima, Piñera, Lydia Cabrera, Novás Calvo, Carpentier, Guillén- que Bustrófedon ha grabado en cinta magnetofónica y que se transcriben bajo el subtítulo "La muerte de Trotsky referida por varios escritores cubanos, años después $\longrightarrow$ antes." Pero hay entre las dos secciones, a mi juicio, una diferencia significativa: en "Rompecabeza", el punto de vista es el de Códac, mientras que en la primera tirada de "Algunas revelaciones" la narración parece asumirse directamente por el autor, que no de otro modo pueden entenderse las páginas en blanco y los juegos tipográficos (como el de la página que se refleja en la de enfrente). Son particulatidades que provienen obviamente del autor y de la manera como concibe el libro; el autor se denuncia de manera bien ostensible en esta declaración de la página 270: "Yo, este anónimo escriba de jeroglíficos actuales, podría decirles más..." No es accidental, en fin, que en el prólogo (visión de un escenario donde se reúnen personajes que aparecerán más adelante en la obra), aquí, en el centro y hacia el final, por medio de una nota, Cabrera Infante nos haga sentir traviesamente su presencia, nos recuerde que es él quien maneja los hilos o, más adecuadamente, hace vivir a sus criaturas. Esta observación sirve de anticipo a ciertas ideas que expondré posteriormente. "Algunas revelaciones" incluye, tras la nueva evocación de Bustrófedon y sus aventuras lingüísticas, las sesiones psiquiátricas "Octava", "Novena" y "Décima", alternadas con dos fragmentos de "Ella cantaba boleros".

"Bachata", aunque apoyada en la visión de Silvestre, es en realidad un extenso diálogo, que parece más bien match de boxeo, entre éste y Cué. Los dos interlocutores (o contendientes) alcanzan igual relieve, $y$ aun se inclinaría uno a conceder la primacía a Cué, si no fuera porque las palabras decisivas las tiene Silvestre al final. Al lector familiarizado con $T T T$, no le parecerá extemporánea la observación siguiente: este diálogo o cuerpo a cuerpo da a ratos la impresión de desarrollarse entre un hombre y su imagen, un individuo y su doble, $o_{2}$ más exactamente, dos hipóstasis de un mismo ser. Uno frente al otro, los dos personajes se reflejan mutuamente, confirmando de manera muy concreta la compleja armazón especular de la obra a que he aludido en otra parte. La salida de este laberinto de espejos y, a la larga, solución a todas las "charadas" anteriores del libro, es lo que se ofrece al lector al final de esta "bachata", cubanismo por fiesta desenfrenada, que alude también aquí, juego típico del libro, a Bach, a la forma musical de la fuga $y$, por asociaciones sucesivas, obvias o insinuadas, al movimiento constante en el auto de Cué Malecón arriba y abajo, a las consideraciones sobre tiempo y espacio y, en definitiva, a los tiempos y espacios de los personajes de la obra. La sa- 
lida que encuentra Silvestre exige una pérdida, la de la amistad de Cué o, a tono con el carácter de conciencia dividida que veo en este pasaje, la ruptura con una parte de esa conciencia, necesario abandono de lastre para llegar a la "clave del alba" en las últimas líneas del monólogo de Silvestre. La identificación Cué-Silvestre queda, por otra parte, más que sugerida por el autor en estos "bocadillos" de los personajes:

- Lo cierto es que ni tú ni yo somos contradictorios. Somos idénticos, como dijo tux amiga Juanita.

- ¿La misma persona? Una binidad. Dos personas y una sola contradicción verdadera.

(P. 419)

En este recorrido general por el texto de la obra, creo haber puesto de relieve relaciones entre sus partes no examinadas hasta hoy, que yo sepa, en otros estudios. Llevaré ahora más lejos este tratamiento. En primer lugar, se impone aquí explicar con más pormenores el grado de dependencia entre esas partes o piezas que he calificado de fundamentales: "Seseribó", "La casa de los espejos" y "Bachata". Sólo al comprender la intima trabazón que existe entre estas secciones, se llegará a precisar el tipo genérico a que pertenece $T T T$, con antecedentes antiguos y prestigiosos (algunos señalados ya por la crítica y el mismo Cabrera Infante).

Indicaba, al referirme antes a los personajes centrales de estas secciones -Ribot, Cué y Silvestre, respectivamente- ${ }_{2}$ cualidades que son comunes en ellos: la pasión por la música, el ejercicio de la inteligencia y la participación más o menos activa en alguna forma de espectáculo (Cué es actor, Ribot es músico en un conjunto de niteclub, Silvestre "revive" constantemente escenas de películas). ¿No son demasiado significativas estas coincidencias? Se puede argüir, tal vez, que estas cualidades comunes son el origen de la estrecha amistad de los personajes. ¿Pero no es, de todos modos, "sospechosa", tan absoluta identidad? Las grandes amistades, como el amor, suelen cimentarse sobre notables diferencias, a veces oposiciones de carácter. ¿No ha buscado el autor por este medio referir ${ }_{2}$ en realidad, estas partes, estos "tigres" a una persona que los contiene y los justifica? $O$, dicho de otra manera, estos tres personajes vienen a ser avatares de la conciencia o de la memoria del autor. No se trata exactamente del tradicional alter ego de la novela con rasgos autobiográficos - aunque la comparación sea, en cierta medida, aceptable-, sino de algo más simple cuanto, de modo paradójico, menos evidente. El autor ha querido recons- 
trùir con su obra un mundo, o el reflejo de ese mundo que sobrevive en su memoria: mundo-reflejo tan profundamente personal, que el autor no aspira a "objetivarlo", pues eso supondría en este caso juzgarlo y explicarlo (algo que, decididamente, evita el libro). La cita de Lewis Carroll, lema de la obra, encuentra así su más plena justificación. Para llevar a cabo su intención, Cabrera Infante ha fragmentado el espejo (conciencia-memoria) y es sólo juntando estos trozos que podemos obtener la visión unitaria. La diferenciación entre los tres protagonistas es en el fondo tan tenue, que, cuando no hay datos específicos, la distinción es difícil para el lector. En el diálogo de "Bachata", por ejemplo, el lector más atento, si quiere adscribir éste o aquel parlamento a Silvestre o a Cué, tendrá en muchas ocasiones que volver atrás y retomarlo en un punto aclaratorio. Por otra parte, no caigo en la ingenuidad de considerar el libro autobiográfico en el sentido más literal, ni pretendo aquí identificar pormenores de la ficción con los de la vida real del autor y hace bien Cabrera Infante en prevenir al lector contra esa tentación. ${ }^{7} \mathrm{No}$, lo que trato de expresar es otra cosa: el libro es autobiografía en cuanto transposición de la memoria o. de una serie de memorias que el autor recompone, en última instancia, con la libertad del inventor de ficciones y con un propósito puramente estético. ${ }^{8}$ Sobre la función que el minucioso recordar ha tenido en la creación de TTT, el texto nos ofrece suficientes claves, por medio, justamente, de Silvestre, el escritor o "recordador":

Lo opuesto a mi, porque me gusta acordarme de las cosas sabiendo que nunca se pierden porque puedo evocarlas debe baber tiempo. Esta es la cosa que es en el presente lo más perturbador y si existe el tiempo que es en el presente lo más perturbador es la cosa que bace al presente 10 más perturbador puedo vivirlas de nuevo al recordarlas y sería bueno que el verbo grabar (un disco, una cinta) fuera el mismo que en inglés, recordar también porque eso es lo que es, que es lo opuesto de lo que es Arsenio Cué. (p. 297)

7 En la entrevista con Rita Guibert, cuando la entrevistadora le pregunta si el libro es autobiográfico, Cabrera Infante lo niega, pero esa negativa parece dirigirse a la actitud simplista de asociar la primera persona del narrador con el yo del autor, atribuyendo al autor todo lo que sucede al natrador (loc. cit., p. 546).

8 Ha dicho Cabrera Infante: 'Mi visión del mundo es la misión del 'Monde' [se refiere al periódico francés]: una misma superstición hebraica nos impide ver otra cosa que la palabra escrita, negando el mundo de la imagen. Pero al periódico (como al escritor) lo inundarán las imágenes, lo están ahogando ya y dentro de muy poco ambos dejaremos de existir. ¿No será porque veo el espejo como la primera y por tanto más terrible imagen? Lo fantástico juega en TTT el mismo rol que la memoria juega en lo fantástico. No hay más que memoria, hasta la imaginación está hecha de memoria". (Entrevista con Albert Bensoussan, loct. cit) 
Me reí. Pero pensé mirando al puerto que hay alguna relación sin duda entre el mar y el recuerdo. No solamente que es vasto y profundo y eterno, sino que viene en olas sucesivas, idénticas y también incesantes. Ahora estaba sentado en la terraza tomando una cerveza y llegó un golpe de brisa, ese viento que viene del mar, cálido, que comienza a soplar al caer la tarde y en asaltos repetidos me llegó el recuerdo de este aire de la tarde, pero fue el recuerdo total porque en uno o dos segundos recordé todas las tardes de mi vida (por supuesto que no las voy a enumerar, lector) en que sentado en un parque leyendo levantaba la vista para sentir la tarde o en que me recostaba a una casa de madera y oía el viento entre los árboles o en la playa comiendo un mango que manchaba mis manos de jugo amarillo o sentado junto a una ventana oyendo una clase de inglés o visitando a mis tíos sentado en una mecedora con los pies sin llegar al suelo y los zapatos nuevos que me pesaban cada vez más, y donde siempre batia esta brisa suave y tibia y salobre. Pensé que yo era el Malecón del recuerdo. (p. 304)

Esta imagen me asalta ahora con violencia, casi sin provocación y pienso que mejor que la memoria involuntaria para atrapar el tiempo perdido, es la memoria violenta, incoercible, que no necesita ni madelenitas en el té ni fragancias del pasado ni un tropezón idéntico a sí mismo, sino que viene abrupta, alevosa y nocturna y nos fractura la ventana del presente con un recuerdo ladrón. No deja de ser singular que este recuerdo dé vértigo: esa sensación de caída inminente, ese viaje brusco, inseguro, esa aproximación de dos planos por la posible caída violenta (los planos reales por una caída física, vertical y el plano de la realidad y el del recuerdo por la horizontal caída imaginaria) permite saber que el tiempo, como el espacio tiene también su ley de gravedad. Quiero casar a Proust con Isaac Newton. (p. 306)

Aunque Silvestre habla de "recordar" como "lo opuesto de lo que es Arsenio Cué", añadiendo después que lo que hace Cué es "memorizar", se trata, al cabo, de opuestos complementarios, de dos funciones de la memoria difícilmente separables. La opinión de Silvestre, por otro lado, es injusta, ya que, como se verá en breve, Cué, en "La casa de los espejos", recuerda a Laura intensa y minuciosamente. Lo cual, a su vez, contradice esta declaración suya de "Bachata": ..." porque si estuvieras, si hubieras estado enamorado no recordarías nada, no podrías recordar siquiera si los 
labios eran finos o gordos o largos" (p. 306). (Estas contradicciones innegablemente refuerzan el carácter de dualidad, o de uno dividido, que he señalado con referencia a "Bachata.")

Entre los recuerdos de que está compuesta la obra, los del amor constituyen el hilo argumental en las narraciones de los tres tigres, o son su común dominador. Se puede ir más lejos todavía y ver estos episodios como etapas de una sola historia de amores, fragmentada entre los tres personajes (Eribó, Cué, y Silvestre). La relación sensual con la ambigua Cuba Venegas, la atracción por Vivian (sin posible satisfacción) y el amor por Laura Díaz, frustrado primero y realizado más tarde, forman como momentos sucesivos de una misma experiencia sentimental. Claro que en el contexto individual de los personajes Cuba y Vivian aparecen como los fracasos de Eribó y Laura como el gran amor perdido por Cué y ganado por Silvestre. Pero hasta qué punto el autor quiere abarcar unitariamente esos recuerdos, lo muestra un pormenor que en obra tan cuidadosamente planeada no puede obedecer a arbitrariedad o distracción. Es el hecho de que Silvestre sueñe, en la página 445, "con los leones marinos de la página ciento uno", cuando la página 101 pertenece a la sección "Seseribó" y lo que alli se presenta es algo que le sucede a Eribó y no a Silvestre (se trata de la visita de Eribó y Cué a Vivian, en la piscina del edificio donde ella vive). Los "leones marinos" son las niñas que rodean a Cué, junto a la piscina, cuando lo reconocen como su ídolo de la televisión. La palabra "Tradittori" puesta al final de la tirada, tiene, pues, en este respecto, un significado inmediato; el autor acaba de traicionarse, y así lo reconoce. Cuando relacionamos esta "traición" flagrante del autor con otras ya mencionadas, más o menos explícitas, se hace evidente su intención de que el lector abandone las trilladas psicologías y sociologías y acepte, comprenda la obra en su totalidad como elaboración de una memoria personal, ordenada "grabación" de su autor. El fenómeno se puede asociar con el observable en Finnegans Wake - libro con el cual TT'T emparienta por algún costado- que, al pretender abarcar la historia de la humanidad en el sueño de H.C.E., traiciona la presencia de otro soñador, James Joyce, quien suple la visión histórica y erudición que faltan a su protagonista.

La historia de amor con Laura Díaz (nótese la resonancia petrarquesca del nombre) ilumina las secciones correspondientes a Cué y Silvestre ("La casa de los espejos" y "Bachata"). Esta historia, como ya he anotado, es una de las más importantes "claves" temáticas de la obra: ella instaura, al final, un orden que podríamos llamar trascendente. Cué recuerda a Laura con la emoción de su belleza y el dolor de su pérdida: 
No tenía la menor idea de quién sería, tanto que iba a dar una excusa y meterme en la máquina, cuando vi una muchacha larga, pobremente vestida de negro, delgada, de pelo castaño claro, casi arena, que sonreía junto a la escalera: yo la había mirado al pasar por su lado, contento de ver aquel cuerpo esbelto y bien hecho y joven, y creo que miré sus ojos grises o castaños o verdes entonces (no, no los miré, porque los hubiera recordado: son sus ojos malva, oscuros, morados los que no puedo olvidar). (pp. 147-48)

Además, ella era viuda - cosa que no vi, por supuesto, como no vi otras cosas que quizá por teléfono habría sabido más que ahora que la tengo abí fijada en el recuerdo: hablando y riendo y el sol cayendo por detrás de su pelo revuelto y del mar, cinco horas más tarde cuando la traía del Mariel, de un almuerzo marinero y tardío, por el Malecón a su casa. (p. 148) ${ }^{\circ}$

No, no había amor entre Laura y yo aquella tarde, todavía. Lo hubo, lo hay, lo habrá, mientras yo viva, ahora. Livia lo sabía, mis amigos lo sabian, toda La Habana/que es como decir el mundo/lo sabía. Pero yo no lo sabía. No sé si Laura lo supo nunca. (p. 150)

Una reminiscencia literaria que contribuye a fijar el carácter de esta relación sentimental, sirviendo a la vez como de su presagio, es la lectura asidua, por parte de Cué, de Across the River and into the Trees. Cué lleva el libro de Hemingway cuando conoce a Livia Roz, quien hace un comentario frívolo a su costa. Este incidente tiene mayor importancia de lo que parece, si se recuerda que precisamente por la tentación de "la carne de Livia" (p. 149), Cué pierde a Laura, por haberlo encontrado ella en un juego erótico con Livia. Cuando Cué habla por primera vez (por teléfono) con Laura, acaba de releer la novela de Hemingway: "La llamé un día cuando terminé de leer por tercera ocasión esta novela conmovedora y triste y alegre que es creo de los pocos libros de veras sobre el amor que se han escrito en el siglo"... (p. 147) ${ }^{10}$

En "Bachata", Laura es el oculto resorte del diálogo-duelo entre Cué y

- El subrayado es mio.

10 El pasaje tiene un señalado aire hemingwayano. Lo veo, en cierto modo, como un "homenaje" a Hemingway, entre los varios que rinde el autor a sus escritores favoritos, de Dante a Raymond Chandler. En este caso, el homenaje está teñido de nostalgia por una época de la juventud del autor, cuando Hemingway era dios tutelar de êl y otros escritores de su generación, algunos grandes amigos suyos entonces. Dos de estos escritores, Lisandro Otero y Silvano Suárez, han publicado libros sobre Hemingway. 
Silvestre. Véase este significativo fragmento que cito a partir de un comentario de Silvestre (conviene recordar que Laura, la antigua modelo, es ahora una conocida actriz) :

-Chico, tiene razón Códac, el Fotógrafo de las Estrellas. En cada actor hay escondido una actriz.

Entendió la alusión, sabía que yo no lo acusaba de afeminado ni nada, sino que conocía en parte o todo su secreto y se calló la boca. Puso una cara tan seria que lo lamenté y maldije mi costumbre de decirle a la gente las cosas mejores en los peores momentos o las cosas peores en los mejores momentos. $\mathrm{Mi}$ arte de ser oportuno. Regresó a la bebida y ni siquiera me dijo, Coño contigo no se puede hablar, sino que se quedó callado mirando el líquido amarillo que hacía amarillo el vaso y que por el color y el olor y el sabor debía ser cerveza, cerveza caliente por el tiempo y la tarde y el recuerdo. Llamó al camarero.

-Otras dos bien frías, maestro.

Miré su cara y vi todavía el fulgor que debió tener Kalikrates o Leo cuando encontró a Aïsa y supo que ella era Ella. Es decir, She. (p. 308)

Laura, en fin, reaparece de manera dominante en el anuncio que hace Silvestre a Cué de su próximo casamiento con ella:

¿Cómo empezar? Era lo que quise decirle toda la noche, todo el dia, desde hace días. Llegó el momento de la verdad. Conozco a Cué. Se sentó nada más que para jugar al ajedrez verbal conmigo. -Vamos. Te estoy esperando. Pitchea. No quiero bolas de saliva. ¿Qué dije? Un ajedrez popular, el beisbol.

-Te voy a decir el nombre de la mujer del sueño. Se llama Laura. Esperé que saltara. Lo esperé desde hace semanas, lo esperé todo el día, por la tarde, por la noche temprano. Ya no lo esperaba. Tenía lo que no tienen ustedes para saberlo: su cara frente a la mía. -Fue ella quien soñó el sueño.

$-i \mathrm{Y}$ ?

Me sentí ridículo, mās que nuinca.

-El sueño, es de ella.

-Ya me lo dijiste. ¿Qué más?

Me quedé callado. Traté de encontrar algo más que refranes y frases hechas, una frase por hacer, palabras, alguna oración regada por 
aquí y por allí. No era ni pelota ni ajedrez, era armar un rompecabezas. No, un juego de bloques de letras.

- La conocí hace días. Un mes o dos, mejor dicho. Hemos salido, salimos juntos. Pienso, creo. No. Me voy a casar con ella. (p. 434)

Laura es, en conclusión, el catalizador que propicia el cambio, el orden que se impone al final. Orden que incluye a la conciencia del creador $y$, en definitiva, a su creación. Laura está en ese amanecer que liquida la última orgía nocturna del libro; en ella encuentra origen esa figuración de orden que es la obra concebida, la que ahora en nuestra lectura está concluyendo: Tres tristes tigres. Así, el final del libro nos remite cíclicamente al comienzo, revelándonos a la vez la posición desde la cual se hace posible la obra y su punto de arranque: ..."y dije, entonces, fue entonces, una palabra, me parece, un nombre de niña (no lo entendí: clave del alba)"... (p. 445). ${ }^{11}$ Para hallar la clave hay que volver a las primeras páginas de la obra, al pasaje que inicia la sección "Los debutantes": el relato que hace Laura Díaz de ciertas aventuras de su infancia en compañía de su amiga Aurelita.

La obra es, por lo demás, un accidentado tránsito por la sombra hacia la luz (el alba salvadora del final). Ese ambiente sombrío, que se presenta de modo más evidente bajo el aspecto de la noche, sintetiza simbólicamente su tema en distintos planos de significación. Porque si en el nivel más inmediato la obra intenta sumergir al lector en el fárrago de La Habana "nocturna" como era hace años, o como el autor lo conoció, la visión que alli se ofrece tiene mayor alcance. En realidad, el lector, guiado por el autor, realiza el descenso a otro infierno, el de Cuba en su fondo de enajenación, violencia, lascivia y tristeza animal (género de tristeza al que apunta el trabalenguas escogido como título del libro). Si este aspecto de Cuba tiene puntos de contacto con el resto de la América Latina (en el más amplio sentido de la expresión), en Cuba, sin embargo - tal vez lo que afirmo deba extenderse a toda la región del Caribese acusan los mencionados rasgos caricaturescamente, como consecuencia de su condición de isla estratégica, que la convirtió en centro de trasiego marinero, escala obligada de expediciones al continente, factoría de la

11 Las alusiones aquí apuntan a otras cosas también, a los libros de Alicia, a Lewis Carroll y a su afición a las niñas; "Las claves del alba" es el título de un libro de Roberto Branly y puede verse como una broma esotérica. Pero como sucede a menudo con Joyce, los significados de ciertas alusiones se amplian y multiplican de modo sorpresivo dentro del todo. Las alusiones o bromas privadas que abundan en TTT se deben considerar, por otra parte, como autobiográficas, según la definición de autobiográfico que intento en este ensayo. 
potencia vecina e importante base naval. El prólogo y el epílogo son, en este sentido, como dos polos, el colectivo y el individual, respectivamente, de este mundo. El cabaret Tropicana del prólogo es como una cápsula (la comba de cristal que lo cubre subraya la impresión) donde se exhiben las ridículas pretensiones y ostentaciones de los que allí se encuentran, o los que allí han llegado, pues Tropicara es la imagen de una aspiración general: la de vivir despreocupada, indiferentemente, en un clima artificial de frío. Por eso se reúnen alli el magnate y el senador Solaún (el "tiburón" que explota a Eribó), el Coronel Suárez Dámera con su esposa (la Beba Longoria de "Los debutantes"), la poetisa y recitadora Minerva Eros, amante del torturador oficial Ventura y la jovon aristócrata Vivian Smith Corona Alvarez del Real, de quien se enamorará Eribó. Políticos, militares, advenedizos, aristócratas, cortesanas, derroche y vulgaridad. Y en medio de todo esto, Códac, el hombre-cámara, de quien me ocuparé en breve. "AArriba el telón!. . . Curtains up!" dice el maestro de ceremonias al final de su introducción o de la introducción al libro: hechas las presentaciones, comienza la función, el show - pequeño teatro del mundodonde reaparecerán estos personajes, sus émulos y sus víctimas. El epílogo es la voz de una conciencia "enajenada" donde resalta ese "ya no se puede más", última frase del libro, aunque no su solución, como creo haber mostrado. Porque "ya no se puede más", Silvestre decide cambiar su vida, rebelarse. Emblemáticos, dentro de este cuadro, son otros personajes y situaciones, como las coristas Mirtila y Livia y, especialmente, la desequilibrada Magdalena Crús, el sbow de Superman y las escenas de violencia que narra Silvestre al principio y al final de la obra, dos experiencias de su infancia (pp. 41-42, 437). En ese contexto adquieren su valor exacto imágenes como la de esa personificación del lado oscuro de la isla que es Cuba Venegas, de quien se nos dice que "es mejor, mucho mejor ver a Cuba que oírla y es mejor porque quien la ve la ama, pero quien la oye y la escucha y la conoce ya no puede amarla, nunca" (p. 278) o aquella del coctel llamado "mojito" ("agua, vegetación, azúcar [prieta], ron y frío artificial"), visto como una "metáfora de Cuba" (p. 321). Conviene añadir que Cabrera Infante no pasa más juicio moral que el implícito en su comprensión de esta realidad - fuerza de su arte- y que la "nostalgia" mencionada en la tapa del libro y una buena dosis de compasión constituyen ingredientes esenciales de su visión.

Pero la obra no se detiene en esta visión local. En ese caso, representaría sólo un curioso documento sociológico, y nada más lejos de su razón de ser. Con método admirable, en el que se destacan las interpolaciones regulares de "Ella cantaba boleros" y las sesiones psiquiátricas, la visión 
del autor salta todas las fronteras y acaba por enfrentar al lector, sencillamente, a los ancestrales terrores y esperanzas de la especie (lo que, a mi modo de ver, explica la universalidad de su éxito). Porque el libro es, por encima o por debajo de todo lo demás, un rito exorcístico con que el autor ha querido purgarse - catarsis en la que pretende hacer partícipe al lector - de los "demonios" o fuerzas oscuras que habitan en nosotros junto a los "ángeles" de la luz, oposición que la obra recoge como dialéctica de la noche y el día (de modo más notable en su parte final). Los pasajes de "Ella cantaba boleros" sirven, sobre todo, este propósito, con su insistente evocación de monstruos de la noche (criaturas abismales, amenazas de las pesadillas), que preside "La Estrella", la Ballena Negra -grotesca versión del tradicional leviatän-, quien, como las sirenas míticas, encanta con su voz en las profundidades lóbregas de los bares. La circunstancia de que estos pasajes sean contados por Códac aparece como una exigencia de la obra inmejorablemente satisfecha por Cabrera Infante. Se requeria aquí el registro objetivo de ese mundo y esos seres y Códac, el fotógrafo, desasido, impasible -él mismo un cruce entre cámara y grabadora - es el medio idóneo para lograrlo sin abandonar la técnica de los testimonios directos, procedimiento que da unidad, a pesar de lo diverso de los materiales, a la "factura" total de la obra.

En cuanto a las sesiones psiquiátricas, como se anticipaba arriba, reflejan y subrayan motivos básicos de la obra. El de la muerte, vista por sus lados más repulsivos, el del cadáver — disecciones de la Escuela de Medicina (p. 144), Bustrófedon sometido a la autopsia- y el del asesinato - la tortura, se evidencia en las sesiones siguientes: "Segunda", con el sueño sobre la carroña del perro quemado, "Quinta", con el hallazgo del esqueleto "que tenía todavía pedazos de carne" y la "Décima", con la anécdota sobre la vaca que matan en la calle y que ha originado en la paciente repugnancia a comer carne. El motivo del rechazo con matices raciales (Vivian y Eribó) se repite en el sueño de las lombrices, de la sesión "Octava". El de los actores (Cué, sus "juegos" y los de los otros) queda sintetizado en la "Tercera" ("¿Doctor, usted cree que yo debo volver al teatro?"...). El de los vagos deseos e infortunios de la infancia y adolescencia femeninas, de la mayor importancia en obra donde figuran tantas mujeres desajustadas, se revela en la "Cuarta" - sueño infantil de la paciente-, "Novena" —-donde la paciente relata su primera experiencia matrimonial, terminando con el recuerdo de su hija, que le es arrebatada por la familia del marido- y "Oncena", que describe la pérdida de la inocencia de una "amiguita" de la paciente (tal vez la paciente misma o un producto de su imaginación, como sugiere ella al final). La figura 
orbicular de la obra se refuerza por el hecho de que la sesión "Oncena" sigue inmediatamente al monólogo final de Bachata", cerrando esta sección. El "nombre de niña" del monólogo nos remite a las niñas de "Los debutantes", pero la sesión "Oncena" sirve de enlace, o, mejor, de trampolín que nos ayuda a dar el salto al comienzo.

En mitad del libro se introducen los juegos linguísticos, las parodias, la filosofía y la muerte de Bustrófedon. Estos pasajes pueden tomarse como entremés (descanso o divertimiento), pero también forman un centro en sentido más profundo que el de su posición en la obra. Bustrófedon es la oculta divinidad que los demás veneran o de la cual son otros tantos reflejos, imágenes de esa imagen del "relajo" total. Bustrófedon es el tradicional "choteo" cubano elevado a categoría trágica. Al margen de los grandes movimientos de la cultura, la vida intelectual de una isla del Caribe se debate entre la hinchada pompa y el juego irrespetuoso. Pero el juego irrespetuoso, parece decir Cabrera Infante, expresa mejor, y no sólo allí, el interés apasionado en las ideas y el arte que han dado perfil a eso que llamamos civilización occidental: "¿Una broma? ¿Y qué otra cosa fue si no la vida de B? ¿Una broma? ¿Una broma dentro de una broma? Entonces, caballeros, la cosa es seria" (p. 264). Desde este ángulo apreciamos debidamente la función de las parodias de escritores cubanos. Lo que se parodia, en el fondo, es lo que hacen Proust, Huxley o Mann con sus consideraciones estéticas sobre la obra de algún personaje de ficción que representa a cierto o ciertos artistas de la época en que escriben. Las tiradas que "traducen", por ejemplo, en Proust, el arte de Bergotte, de Elstir, o de Vinteuil, son aquí "traducciones" en broma de escritores cubanos conocidos. La broma, por otra parte, no supone siempre desprecio; en algunos casos implica admiración y creo que ocurre así en estas parodias (principalmente las de Lydia Cabrera, Novás Calvo y Virgilio Pinera). El origen de estas bromas es, a fin de cuentas, algo más radical: la desproporción, entre lo que algunos llaman (a llamamos) "literatura cubana" y la vieja, original y prestigiosa literatura europea.

Desde luego que esta bufonada de Bustrófedon y sus ramificaciones por el libro tiene también otros alcances -a la postre, de "cosa seria"-, como la corriente de literatura humorista en la cual se inserta, señalada ya por la crítica (Rabelais, Quevedo, Swift, Sterne, Mark Twain, Lewis Carroll, Jarry). Y ya en el plano de los antecedentes y las tradiciones, regresemos a mi noción de que el libro constituye un curioso ejemplar cruzado de novela y autobiografía, de suerte que es a la vez esas dos cosas y algo muy distinto de las dos. Para comprender mejor este cruce genérico, basta invocar algunas obras que, cada una a su modo, lo ha realizado. 
En primer lugar, piensa uno en algunas obras de la picaresca tardía donde las aventuras se presentan como "documentales", tal el Estebanillo González o la fabulosa Vida de Diego de Torres Villarroel. Con carácter especial se debe considerar a Tristam Shandy, que suele citarse a propósito de TTT. La obra de Sterne es, en suma, como ve justamente John Stedmond, un tour de force sobre el acto mismo de la creación del libro y las operaciones mentales puestas en juego para su escritura, en relación con el lector. ${ }^{12} \mathrm{La}$ obra, dicho de otra forma, se propone, mediante la "autobiografía" de su protagonista, como ostensible manipulación por el autor de su experiencia creadora y, por ello, de una compleja experiencia personal. (Lo autobiográfico es, en este libro, de índole muy particular, abstracta quizás; ejemplifica bien, por ello, el amplio sentido que doy al concepto.) Cabrera Infante, de manera semejante, utiliza los datos de su memoria - transformándolos según las necesidades de su obra- para mostrar algo así como el proceso de su reconstrucción artística. Infundiendo esta memoria en diferentes personajes, presentando ciertos monólogos narrativos en forma interrumpida, disponiendo, en fin, estos materiales a su conveniencia, como el jugador su manojo de naipes, el autor instaura un "orden desordenado" que refleja también las dificultades del esfuerzo de "recordar". El procedimiento tiene gran parecido con el del montaje cinematográfico - el autor es por pasión y oficio un hombre de cine- a causa de los peculiates efectos que logra la asociación por proximidad de diferentes contenidos ("tomas") en una sucesión ("secuencia").

Por último, y aún más estrechamente, como consecuencia de lo que vengo sosteniendo, hay que poner a TTTT en relación con Portrait of the Artist as a Young Man y $A$ la recherche du temps perdu, esos dos pilares contemporáneos de la memoria-ficción. W.Y. Tindall, que ha expuesto ejemplarmente la relación arte-pensamiento en Joyce, afirma a propósito de Stephen Dedalus: "It has seemed odd to some critics that one who commends impersonality should write about himself. But, as we have seen, there is no paradox here. By aesthetic distance, the personal, becoming symbolic and formal becomes dramatic". ${ }^{13}$ Importa subrayar que al hablar

12 "His purpose - dice Stedmond- was, not to tell a story, but to examine the drama inherent in the very act of writing a book-the give and take between author and reader, the eager efforts of the one to overcome the stolid indifference of the other. Thus Sterne was extremely conscious not only of the workings of his own mind during the act of creation but also of the possible actions and reactions in the minds of his readers". (The Comic Art of Laurence Sterne, University of Toronto Press, 1967, p. 28).

13 James Joyce, His Way of Interpreting the Modern World, New YorkLondon, 1950, p. 19. 
de "distancia estética", Tindall establece implícitamente la diferencia de $A$ Portrait... respecto a la tradición más directamente autobiográfica de las novelas de "formación del carácter". En cuanto a la obra de Proust, Leo Bersani se refiere a ella en términos semejantes a los que he aplicado arriba a TTT: "Such a work would be novelistic and directly autobiographic without really being either one."14

Estas coordenadas no sólo ayudan a situar genéricamente a $T T T$, sino además a fijar mejor sus rasgos distintivos. $Y$ es que el libro, como toda obra de creación genuina, una vez establecidas sus filiaciones, evidencia más que nunca su originalidad.

JULIO MATAS

University of Pittsburgh

14 Marcel Proust, The Fictions of Life and of Art, New York, 1965, p. 4. Por su importancia en relación con lo que expongo aqui, reproduzco otras palabras suyas sobre $A$ la recherche. ..: "To substitute a history of the author's sensibility for the invented situations and characters of traditional fiction: it is this impatience with the very materials of story-telling, the wish to bypass imaginary plots and write a work of self-expression, that perhaps most sharply distinguishes Proust from earlier practitioners of the novel" (op. cit., p. 3 ). 